Barbara Brezna $\cdot$ Ohgew Kweon $\cdot$ Robin L. Stingley •

James P. Freeman · Ashraf A. Khan • Bystrik Polek •

Richard C. Jones $\cdot$ Carl E. Cerniglia

\title{
Molecular characterization of cytochrome P450 genes in the polycyclic aromatic hydrocarbon degrading Mycobacterium vanbaalenii PYR-1
}

Published online: 28 June 2006

(C) Springer-Verlag 2006

Due to an unfortunate error most of the entries in the pipA column of Table 1 were incorrect. The correct table is printed below.

Table 1 Mycobacterium strains used in this study that were screened for the presence of cytochrome P450 genes and nidA and nidB genes

\begin{tabular}{|c|c|c|c|c|c|c|}
\hline \multirow[t]{2}{*}{ Strain } & \multirow[t]{2}{*}{ Substrate or other characteristic } & \multicolumn{5}{|c|}{ Detection of } \\
\hline & & $\overline{\operatorname{nid} A}$ & $\operatorname{nid} B^{\mathrm{d}}$ & $\operatorname{pip} A^{\mathrm{e}}$ & $\operatorname{cyp} 150^{\mathrm{f}}$ & $\operatorname{cyp} 51^{\mathrm{g}}$ \\
\hline M. aurum (ATCC 23366) & Type strain & $(-)$ & $(-)$ & - & + & + \\
\hline M. austroafricanum (ATCC 33464) & Type strain, related to $M$. vanbaalenii & $(-)$ & $(-)$ & + & + & + \\
\hline M. austroafricanum GTI- $23^{\mathrm{a}}$ & PAHs & + & + & + & - & - \\
\hline M.chlorophenolicum PCP-1 (ATCC 49826) & Polychlorinated phenols & $(-)$ & $(-)$ & + & - & + \\
\hline M. flavescens PYR_GCK (ATCC 700033) & PAHs & $(+)$ & $(+)$ & - & + & - \\
\hline M. frederiksbergense FAn9T (DSM 44346) & PAHs & $(+)$ & $(+)$ & - & + & + \\
\hline M. gilvum (ATCC 43909) & Type strain & - & - & - & + & - \\
\hline M. gilvum BB1 (DSM 9487) & PAHs & $(+)$ & $(+)$ & - & + & - \\
\hline M. petroleophilum (ATCC 21497) & $n$-paraffins & $(-)$ & $(-)$ & - & + & + \\
\hline M. smegmatis $\mathrm{mc}^{2} 155$ (ATCC 700084) & Transformation host & - & - & + & + & + \\
\hline M. vaccae JOB-5 (ATCC 29678) & $\begin{array}{l}\text { Gaseous, long chain, cycloparaffinic and monoaromatic } \\
\text { hydrocarbons }\end{array}$ & $(-)$ & $(-)$ & + & + & + \\
\hline M. vanbaalenii PYR-1 (DSM 7251) & PAHs & $(+)$ & $(+)$ & + & + & + \\
\hline $\begin{array}{l}\text { Mycobacterium sp. 7E1B1W (ATCC } \\
\text { 29676) }\end{array}$ & Gaseous and long chain hydrocarbons & $(-)$ & $(-)$ & - & + & - \\
\hline $\begin{array}{l}\text { Mycobacterium sp. PAH } 2.135 \text { (RJGII- } \\
135)^{\mathrm{b}}\end{array}$ & PAHs & $(+)$ & $(+)$ & - & - & + \\
\hline
\end{tabular}

abtained from Dr. B. W. Bogan at the Gas Technology Institute in Des Plaines, Illinois; ${ }^{b}$ from Dr. D. Warshawsky at the University of

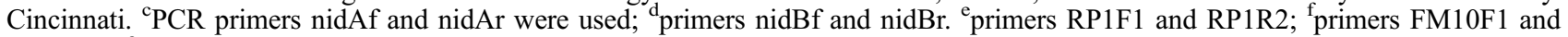
FM10R2, " primers Cyp51F and Cyp51R " +" PCR product of expected size was present, "-" PCR product of expected size was not obtained. In brackets are the cumulative PCR and Southern hybridization results from the previous study as follows: " $(+)$ " the studied gene is present (Brezna et al., 2003). "(-)" the studied gene is not present (Brezna et al., 2003)

The online version of the original article can be found at: http://dx. doi.org/10.1007/s00253-005-0190-8.

B. Brezna · O. Kweon · R. L. Stingley · A. A. Khan ·

C. E. Cerniglia $(\bowtie)$

Division of Microbiology, National Center for Toxicological

Research, US Food and Drug Administration,

3900 NCTR Road,

Jefferson, AR 72079, USA

e-mail: ccerniglia@nctr.fda.gov

Tel.: $+1-870-5437341$

Fax: +1-870-5437307
B. Brezna $\cdot$ B. Polek

Institute of Molecular Biology, Slovak Academy of Sciences,

84551 Bratislava, Slovakia

J. P. Freeman

Division of Biochemical Toxicology, National Center for

Toxicological Research, Food and Drug Administration,

Jefferson, AR 72079, USA

R. C. Jones

Division of Systems Toxicology, National Center for

Toxicological Research, Food and Drug Administration,

Jefferson, AR 72079, USA 